\section{Annual Meeting Checklist}

The 2000 Annual Meeting in Washington, DC, will be upon us quickly. Have you made all of your arrangements? Use this handy checklist to make sure.

\section{$\square$ Preregistration}

All individuals planning to attend the meeting must preregister before August 11, 2000.

You must be a current member in order to qualify for member rates. Register via our secure online form at http:// www.apsanet.org.

\section{Hotel Reservations}

The 2000 meeting will be headquartered at the Marriott Wardman Park and Omni Shoreham hotels. They will fill up quickly, so register early. You must be an APSA member to receive the APSA rate. You can make your reservations online at www. apsanet.org/mtgs/hotels.cfm or call the APSA Housing Bureau at (800) 492-7886.

\section{$\square$ Airline Reservations}

\section{Conventions in America}

(CIA) is the official travel agency of the 2000 Annual Meeting. Call CIA and receive $5 \%$ to $10 \%$ off the lowest fares on American, United, or US Airways. To make your reservations call (800) 929-4242 and ask for Group \#593.

\section{Paper Presenters}

\section{$\square$ Submit Your Paper to PROceedings}

All individuals presenting papers at the 2000 meeting should submit a copy of their paper to PROCeedings, the online collection of Annual Meeting papers. The submission process opens July 1 . Be sure to consult the submission web site at http://papers. tenj.edu

\section{Buche Institute Earns New Funding, Expands, and Moves to Duke in 2001}

The National Science Foundation has awarded Paula McClain a threeyear $\$ 330,000$ grant to support continued operation and expansion of the Ralph Bunche Summer Institute (RBSI), a five-week academic program designed to introduce exceptional minority undergraduates to graduate study in political science and to encourage them to apply to $\mathrm{Ph} . \mathrm{D}$. programs in the discipline.

The new funds will be used to increase the enrollment in the 14year-old program from a maximum of 15 students each year to a maximum of 20 and also expand eligibility from African Americans and Latinos to Native Americans.

This year's Institute will be held at the University of Virginia, where it has been located for the past five years. Although the program will move to Duke University beginning in 2001, Dr. McClain will continue as its director.

Dr. McClain has been tireless in her efforts to secure funds for the Institute and improve its offerings. The efforts on behalf of and donations of resources for the program by UVA President John Casteen, Provost Peter Low, Vice Provost Alex Johnson, and members of the department of government and foreign affairs have also done much to make RBSI a success.

Funds for the Institute come from the NSF, the host institution, and the American Political Science Association. Professor McClain, APSA, and all those affiliated with RBSI thank NSF program officers Bonney Sheahan and Frank Scioli for their continued support.

\section{Russian Educators Visit APSA}

On March 28, 2000, APSA welcomed a group of Russian educators to the national office for a discussion of civic education.

Sue Davis, APSA's director of international programs, officially welcomed the group and briefly discussed the work of the Association. Next, APSA Director of Educational and Professional Development Sheilah Mann initiated an open-ended discussion of civic education programs in the United States and Russia during which topics of resource development, professional training, and standards setting were addressed. Dr. Jeffrey Reed of American University ended the meeting with a reading of his paper, "Dealing with Minority Rights and the Challenges of Rewriting History" and a lively comparative discussion of Russian and American approaches to minority issues.

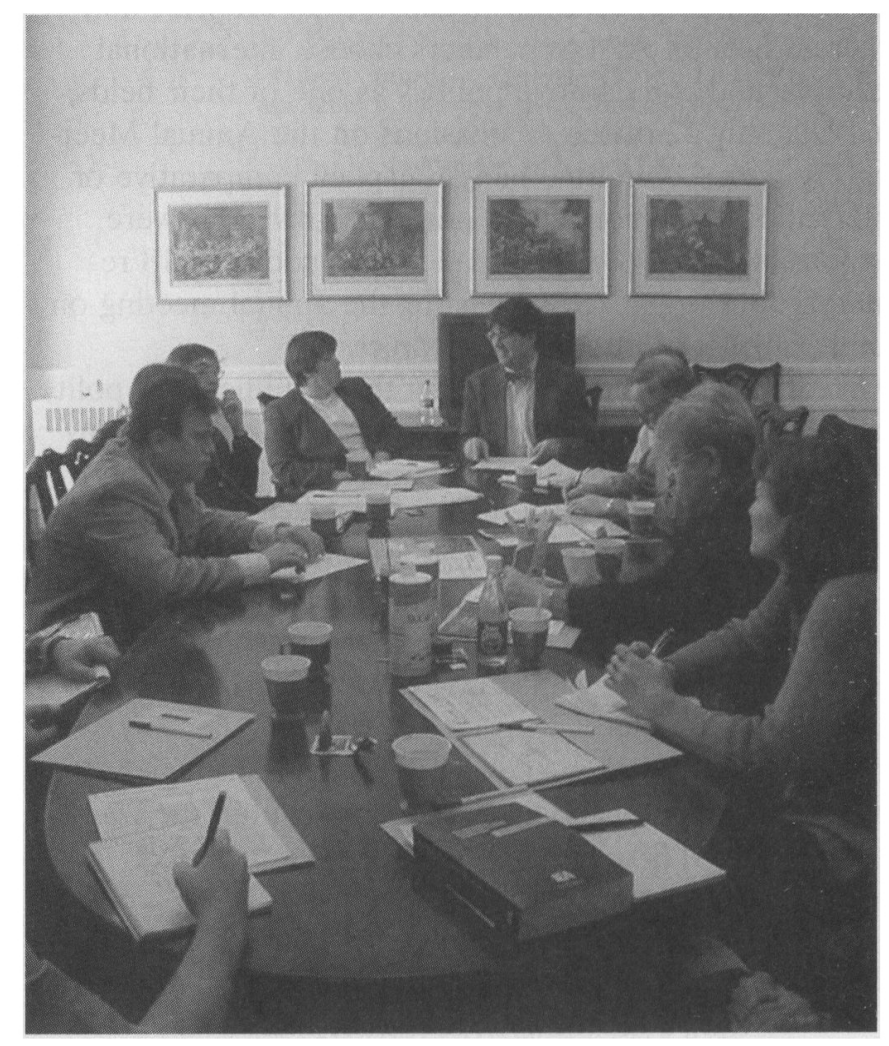

Russian educators visit APSA as part of the CIVITAS project. 